\title{
(t)
}

\section{SERVIÇO SOCIAL E MOVIMENTOS SOCIAIS: REFLEXÕES SOBRE EXPERIÊNCIAS DE EXTENSÃO UNIVERSITÁRIA'}

\author{
Social service and social movements: reflections on the \\ experiences of university outrearch
}

Katia Iris Marro²

\section{RESUMO}

Este artigo baseia-se numa pesquisa introdutória que se propôs mapear e conhecer algumas experiências de estágio e extensão de um conjunto representativo de Cursos de Serviço Social de Universidades Públicas do país realizadas junto a movimentos sociais na atualidade. A pergunta pela relação da profissão com os movimentos e organizações dos grupos subalternos surge no debate como um dos desdobramentos do processo de reconceituação latino-americano das décadas de 1960-1970, dando lugar no período subsequente à criação de experiências de trabalho (inclusive universitárias) que incidem significativamente no redimensionamento crítico do perfil profissional dos assistentes sociais. Partindo da constatação de que avançada a década de 90 esse debate aparece paulatinamente adormecido, num complexo cenário de regressão

\footnotetext{
' Este artigo resgata alguns debates trabalhados no relatório de pesquisa da nossa autoria, intitulado Serviço Social em movimento: experiências universitárias de trabalho e articulação com movimentos e organizações das classes subalternas na contemporaneidade. Relatório de Pesquisa (UFF-Puro, Rio das Ostras, 2011). A pesquisa mencionada contou com a participação e inestimável contribuição da aluna bolsista de iniciação científica, Natália da Silva Pessoa, do Curso de Serviço Social do Puro (UFF). ${ }^{2}$ Assistente Social. Professora Adjunta do Curso de Serviço Social do Pólo Universitário de Rio das Ostras, da Universidade Federal Fluminense (Puro-UFF). E-mail: <katiamarro@gmail.com>.
} 
social - produto das contrarreformas neoliberais que se afirmam no país - que será paulatinamente contestado nos alvores do novo século pelo protagonismo dos movimentos sociais da região, nos perguntamos: que significado adquire hoje para o Serviço Social essa relação com os movimentos sociais na perspectiva da busca do seu redimensionamento crítico?

\section{PALAVRAS-CHAVE}

Serviço Social. Movimentos Sociais. Universidade Pública. Extensão universitária.

\section{ABSTRACT}

This article is based on an introductory research that proposes mapping and learning about some practice and extension work experiences, carried up along with social movements, of a significant set of Social Work courses in Public Universities from all over the country. Questioning about the relationship between Social Work and movements and organizations of subaltern groups, raises from debates as one of the consequences of the Latin American process known as reconceptualization during the 60's and 70's, allowing, subsequently, the generation of work experiences (even at universities) that consequently affect critical rescaling of the professional profile of social workers. Starting from the verification that during the 1990 s this debate was gently deaden, in a complex scenario of social regression - produced by the neo-liberal counter-reforms gaining strength in the country- that would gently be contested in the beginning of the new century by the region's social movements leading role, we ask ourselves: What meaning does it acquire today, for Social Work, that relationship with social movements in the perspective of search for its critical rescaling?

\section{KEYWORDS}

Social Work. Social Movements. Public University. Extension. 


\section{INTRODUÇÃO}

O trabalho que apresentamos baseia-se numa pesquisa introdutória acerca das potencialidades atuais da relação do Serviço Social com os movimentos e lutas das classes subalternas, tendo como ponto de partida a hipótese de que a mesma teve nas décadas precedentes consideráveis impactos no redimensionamento crítico da profissão. Assim, nossa motivação central foi destrinchar - com foco numa pequena amostra de experiências universitárias de estágio e extensão - o significado que adquire hoje, para o Serviço Social, essa relação à luz das profundas transformações sócioestruturais vigentes, as quais se expressam tanto nas condições materiais de estruturação dos conflitos de classes - e nas identidades de luta dos sujeitos - quanto na própria questão social. Transformações essas que desafiam os clássicos parâmentros interventivos e as funções sociais da profissão.

Para compreendermos as potencialidades atuais da relação do Serviço Social com os movimentos sociais, devemos buscar na história recente indicações de como a mesma foi processada nos debates profissionais das décadas passadas ${ }^{3}$. Constatamos que a temática - inicialmente tratada de forma teoricamente imprecisa e subestimando as condições objetivas que determinam o exercício profissional, mas adquirindo uma maior maturidade teórico-política nas décadas subsequentes - se recoloca como uma possibilidade de redimensionamento ético-político, teórico-metodológico e interventivo da profissão. Porém, uma vez avançada a década de 1990, observa-se um gradual decréscimo das experiências de trabalho e das produções que buscam qualificar o significado sócio-profissional dessa relação, acompanhando uma tendência que aponta o seu próprio refluxo, à luz das profundas transformações na dinâmica do capitalismo, na estruturação da luta de classes, na identidade de luta dos grupos subalternos, no Estado e nas políticas sociais.

Qual é o significado atual da relação do Serviço Social com os mo-

\footnotetext{
${ }_{3}^{3}$ Confronte Tofik (1981), Lima et al. (1982), Raichelis \& Rosa (1982; 1985), Moises \& Serra (1987), Faleiros (1985; 1992), Serra (In: V. V. A. A., 1989), Silva e Silva (1995), Duriguetto (1996), Abreu (2002), Cardoso \& Lopes (2009), Bravo \& Matos (2010).
} 
vimentos sociais? A partir dessa interrogação, buscamos mostrar que os traços de luta e resistência que esses sujeitos acionam no enfrentamento da questão social abrem novos horizontes para o exercício profissional - tensionam as correlações de força institucionais; colocam novas requisições que desafiam os clássicos procedimentos de intervenção; questionam as rotinas que reproduzem relações clientelistas orientadas à passivização dos sujeitos coletivos -, assim como trazem conhecimentos e competências que enriquecem o perfil profissional.

Dessa forma, o trabalho profissional articulado aos movimentos sociais deve assumir o desafio da incorporação, na nossa formação universitária e nos diversos âmbitos de atuação profissional, das demandas e reivindicações das classes subalternas nos seus processos de organização, significando a possibilidade de criação de novos espaços de intervenção. Assinalamos que essas estratégias constituem uma possibilidade real de criação de novas bases de legitimidade da profissão junto aos grupos subalternos, afirmando outras relações pedagógicas (ABREU, 2002) com os movimentos sociais que possam reforçar sua auto-organização. O compromisso da categoria com as lutas sociais e com a mobilização popular significa um momento importante do processo de concretização dos princípios apontados no projeto ético-político, possibilitando, inclusive, a potenciação e qualificação da própria organização política da mesma.

Através de que atividades, competências e perspectivas de trabaIho o Assistente Social pode contribuir e reforçar as lutas das classes subalternas? Este interrogante orientou nossas reflexões, buscando sistematizar essa contribuição particular do Serviço Social.

Uma perspectiva de análise fundamental para a profissão é aquela que recupera a questão social a partir dos processos de luta e organização dos grupos subalternos. Essa lente nos permite reconstruir: suas manifestações imediatas a partir das formas de enfrentamento e resistência de classe; uma crítica implícita nas suas práticas aos padrões vigentes de intervenção do Estado e do empresariado; os focos do conflito social que serão alvo das estratégias de políticas sociais que venham a se acionar como respostas privilegiadas pelas 
classes dominantes em face dessas expressões da luta de classes (MARRO, 2009). Através de estudos socioeconômicos, laudos, pareceres, pesquisas e informes sociais, os assistentes sociais podem contribuir dando visibilidade às reivindicações dos movimentos em torno das suas condições de vida e de trabalho, assim como sistematizando uma crítica dos modos privilegiados pelas classes dominantes no enfrentamento da questão social.

Em segundo lugar, analisamos a importância da articulação do Serviço Social com as lutas sociais, como uma possibilidade de ampliação e potenciação dos horizontes institucionais da intervenção profissional: mediante a formação de alianças com os segmentos de classe organizados é possível apostar na transformação das correlações de força institucionais na perspectiva da ampliação da ingerência da participação popular nas decisões e da reversão da histórica relação subalterna desses setores com o poder público.

Nessa mesma direção, reconstruímos o significado das tarefas vinculadas à socialização de informação e conhecimentos, as quais, somadas à prestação de assessoria técnica e política aos movimentos sociais, afiguram-se como instrumentos necessários para o fortalecimento e qualificação da sua participação política (BRAVO; MATOS, 2010).

Também destacamos as atividades de educação popular e formação política, assim como aquelas orientadas à potenciação da mobilização popular e da organização coletiva em torno de necessidades e reivindicações por melhores condições de vida: cursos de formação política; palestras; assembleias e instrumentos de organização comunitária; fóruns de debate; oficinas de capacitação técnica e política. Referimo-nos a um conjunto de atividades que também se estruturam em função da constituição de sujeitos coletivos e da qualificação de uma intervenção mais ativa na vida político-social por parte dos mesmos (CARDOSO; MACIEL, 2009).

Como se materializam essas perspectivas de trabalho para o Serviço Social na atualidade? Finalmente chegamos nas experiências universitárias de estágio e extensão que vêm investindo no trabalho junto aos movimentos sociais, como uma das suas expressões. 


\title{
A ARTICULAÇÃO COM OS MOVIMENTOS SOCIAIS PELA VIA DA EXTENSÃO
}

\begin{abstract}
Abordaremos algumas características de uma pequena amostra de experiências universitárias que vêm trabalhando com movimentos sociais ${ }^{4}$, a partir de um conjunto de eixos de análises, que se referem: ao perfil dos professores que coordenam esses projetos; ao vínculo institucional e os recursos que os sustentam, assim como aos sujeitos sociais envolvidos; aos objetivos e antecedentes históricos; às competências e atividades desenvolvidas pelos docentes e discentes; ao significado desses projetos, do ponto de vista do perfil profissional, no âmbito do Serviço Social.
\end{abstract}

Em primeiro lugar, gostaríamos de destacar a importância que desenvolveram na década de 1980 as chamadas experiências piloto de trabalho e articulação do Serviço Social com movimentos sociais, organizadas a partir de Universidades Públicas e Instituições de Ensino Superior. Ao calor da efervescência da época histórica, as necessidades dos subalternos penetram na agenda universitária de importantes segmentos do Serviço Social. Dessa forma, fazen-

\footnotetext{
${ }^{4}$ A partir da elaboração de um questionário, estabelecemos contatos com os coordenadores dos seguintes projetos e programas: Programa de Apoio à Reforma Urbana (criado em 1992) e Universidade Popular em Direitos Humanos (criado em 2010), ambos da Universidade Federal de Pará (UFPA), em parceria com movimentos urbanos e populares da cidade de Belém (SILVA, 2009); Curso Teoria Social e Produção de Conhecimento (criado em 2004) e Projeto Integrado de parceria em atividades de ensino, pesquisa e extensão com o Movimento dos Trabalhadores Sem Terra (MST) (2006-2009), ambos da Universidade Federal do Rio de Janeiro (UFRJ), em parceria com este movimento (DAL MORO; ACOSTA, 2005); Assessoria do Serviço Social nas atividades desenvolvidas pelo Comitê de Participação Popular (criado em 2010), da Universidade Federal de Juiz de Fora (UFJF), em parceria com movimentos dessa região. $\mathrm{Na}$ análise, resgatamos também elementos de projetos de extensão da universidade em que lecionamos, a Universidade Federal Fluminense, Pólo Universitário de Rio das Ostras (UFF-Puro): Curso de formação política para militantes da saúde pública (2008)(CRUZ, 2008), Observatório de Lutas Sociais: constituição de sujeitos coletivos e políticas públicas (2008-2009) (BICUDO, 2008), Assessoria em questões de cidadania a movimentos sociais e populares: parcerias inter-universidades para a gestação de processos de formação política e humana para militantes sociais (criado em 2010) (FARAGE et al., 2010). Dessa forma, este trabalho não se propôs dar conta de um mapa exaustivo da totalidade de Cursos de Serviço Social de Universidades Públicas (nem da totalidade de projetos dessa natureza que existem no interior dos referidos cursos) que atualmente estabelecem parcerias de trabalho com movimentos sociais. Nosso esforço é apenas uma amostra representativa das iniciativas que vêm sendo desenvolvidas na atualidade, na direção de dar maior visibilidade a uma temática pouco trabalhada na última década. Além disso, vale a pena mencionar a dificuldade de aceder a dados e informações dos projetos pesquisados, uma vez que, num contexto de ausência de recursos para o desenvolvimento desta pesquisa, temos dependido da disponibilidade (e da boa vontade) dos colegas professores que gentilmente dispuseram um espaço de suas extenuantes jornadas de trabalho para responder ao nosso questionário e socializar seus trabalhos.
} 
do referência à articulação com os movimentos urbanos de Belém, uma das nossas entrevistadas afirma:

\begin{abstract}
A história do PARU começa em 1981 [... ]. É uma efervescência que a própria cidade vivia. 1981 é o primeiro congresso da Comissão dos Bairros de Belém [...]. Então a nossa relação ela começa exatamente com o processo organizativo de criação de associações de moradores [...]; nós [curso de Serviço Social] participamos ativamente do processo de organização delas 5 .
\end{abstract}

Pela via privilegiada da ação extensionista - mas envolvendo também práticas de ensino, em um primeiro momento ${ }^{6}$, e de pesquisa, posteriormente com a criação de programas de pós-graduação -, profissionais, professores e alunos de Serviço Social preocupados pela vinculação do exercício profissional com a luta e organização das massas subalternas participaram de experiências de trabalho e formação profissional, dentre as quais podemos destacar algumas pioneiras: o Trabalho junto ao pescador artesanal da Ilha de São Luís, desenvolvido pelo Departamento de Serviço Social da Universidade Federal de Maranhão (UFMA), no período de 1979 a 1983 (CARDOSO; LOPES, 2009, p. 465); o Programa de Apoio à Reforma Urbana (PARU), estruturado na década de 90, mas cujas atividades iniciais datam desde essa época, envolvendo professores de Serviço Social da UFPA; a experiência do Campo Piloto Loteamentos Clandestinos - Setor Parelheiros da Faculdade de Serviço Social da PUC-SP, no ano 1981 (RAICHELIS; ROSA, 1982; 1985).

Nos anos recentes, os cursos de Serviço Social das seguintes universidades têm desenvolvido experiências de trabalho com movimentos sociais: ao trabalho mais consolidado de universidades como a UFMA e a UFPA, soma-se o trabalho desenvolvido pelos

\footnotetext{
${ }^{5}$ Entrevista coletiva realizada a integrantes do Paru, da UFPA, Brasília, agosto de 2010.

${ }^{6} \mathrm{Na}$ década em questão, em diversos cursos de Serviço Social pode se observar essa vinculação entre ensino e extensão, cujos projetos de extensão nascem e se estruturam também como campos de estágio, contando, inclusive, intervenções na área com uma forte presença dos docentes responsáveis. Uma das nossas entrevistadas assinala: "Os nossos campos de estágio nasciam e se estruturavam como extensão; [... ] a concepção do ensino da prática profissional ele era dado inclusive por essa relação entre o ensino teórico, de reflexão teórica, e de experimentação, no sentido de que era o professor, também, envolvido diretamente com o aluno, que exercitava essa prática profissional" (entrevista coletiva realizada a integrantes do PARU, da UFPA, Brasília, agosto de 2010).
} 
cursos da Universidade Federal de Sergipe (UFS), da UFRJ, da UFF de Niterói e de Rio das Ostras, da Universidade Estadual do Rio de Janeiro (Uerj), da UFJF, da Universidade de Estado de São Paulo (UNESP-Franca), da Universidade Federal de Santa Catarina, dentre tantas outras.

Conforme assinalado, as experiências pesquisadas através do questionário representam um universo pequeno, entretanto, algumas inferências podem ser feitas a partir desse material de pesquisa e de outras fontes que complementam a análise.

\section{O PERFIL DOS COORDENADORES}

Um elemento a ser resgatado sobre o perfil dos professores que coordenam as atividades de estágio e extensão junto a movimentos é o fato de que cada docente possui formação de pós-graduação (Doutorado), estando sua área de pesquisa e atuação profissional relacionada com a temática em questão, articulando-a inclusive num campo maior de problematização que inclui questões como Capitalismo contemporâneo e Luta de Classes, Cidadania, Estado e Sociedade Civil, Democracia, Política Urbana e Habitacional, Questão Agrária e sua relação com o Serviço Social. Igualmente interessante é mostrar que esse mesmo universo responde positivamente à pergunta que indaga acerca de possíveis experiências de militância na sua trajetória, resgatando movimentos como o MST, o movimento sindical (docente e de servidores públicos), os movimentos urbanos e populares - sendo que um dos coordenadores destaca sua experiência partidária no PT (entre a década de 1980 e início da de 1990). Este dado mostra uma característica comum que expressa uma provável identidade com as lutas populares e os processos de organização dos subalternos por parte dos seus coordenadores. 


\section{VÍNCULO INSTITUCIONAL, RECURSOS E SUJEITOS SOCIAIS ENVOLVIDOS}

Outro elemento que merece destaque diz respeito ao vínculo institucional e aos recursos fornecidos pela Universidade; elementos que podem dar uma noção acerca das possibilidades de continuidade e permanência dessas experiências. O formato institucional que sustenta o trabalho é fundamentalmente de convênios e parcerias entre alguma instância universitária (Escola ou Faculdade de Serviço Social, Projeto ou Programa de Extensão, Universidade Federal) e os movimentos em questão, sendo que os recursos contemplam, na sua grande maioria, recursos humanos e materiais e bolsas para alunos de graduação envolvidos no projeto. Apenas um único projeto (vinculado à UFRJ) prevê também partidas orçamentárias específicas e contribuições de Fundação Universitária.

Essa pequena amostra não está descolada da realidade atual da extensão universitária, subalternizada em relação às práticas de pesquisa (ou em relação àquelas que implicam venda de recursos e serviços), retratando marcas de certo perfil de Universidade Pública elitista e distante das principais necessidades sociais do seu tempo. Dessa forma, reflete uma dinâmica de financiamento que se concentra, sobretudo, na garantia de bolsas para alunos de graduação, podendo ser complementado com a utilização de recursos materiais que a própria instituição porta. Inclusive, essa é uma realidade que se expressa também nas experiências extensionistas mais antigas, como no exemplo do PARU que data de 1992.

Também podemos observar que os limites em matéria de financiamento institucional não são, necessariamente, um obstáculo para a realização e desenvolvimento desses projetos - os quais se relacionam com compromissos e objetivos que supõem significativas apostas políticas, éticas e profissionais dos docentes e discentes envolvidos -, porém se materializam numa sobrecarga de trabalho e de responsabilidades sobre esses sujeitos, nem sempre devidamente reconhecida pelas universidades públicas às quais se vinculam.

Essas constatações se tornam mais problemáticas se considerarmos a diversidade e amplitude de sujeitos e instituições envolvidos 
nos projetos de extensão analisados, expressando um compromisso (a) com a formação de alunos, (b) com a articulação interinstitucional e o trabalho interdisciplinar, (c) com as demandas e necessidades sociais daqueles que não têm acesso à educação pública, (d) com o enriquecimento da função social da universidade e (e) com a consolidação de práticas coletivas de trabalho que vão à contramão das tendências produtivistas vigentes em muitas instituições de ensino.

Constatamos que a totalidade das experiências pesquisadas envolve articulações com instituições diversas que participam do planejamento, organização e execução das atividades previstas referimo-nos a parcerias: com a Escola Nacional Florestan Fernandes (ENFF); com projetos de pesquisa ou extensão e professores e alunos de outras universidades públicas; com profissionais e instituições assistenciais; com movimentos populares e suas entidades associativas. As mesmas, na sua totalidade, incorporam alunos de graduação e/ou pós-graduação em Serviço Social, incluindo, em alguns casos, alunos de outras áreas (Economia, Antropologia, Educação, Comunicação, Geografia, Ciências Sociais, Direito), sendo previstas atividades de formação acadêmica e acompanhamento desses estudantes. Por sua vez, ao focarmos o público-alvo das atividades realizadas por esses projetos, encontramos: lideranças de movimentos sociais do Brasil; estudantes; técnicos de órgãos governamentais que atuam nas políticas públicas; integrantes de ONGs e conselhos de políticas públicas; comunidades que vivem em áreas de risco, observando o empenho dessas equipes na realização da função social da Universidade Pública.

\section{OBJETIVOS E ANTECEDENTES HISTÓRICOS}

Dentre os antecedentes históricos e os motivos que levaram à construção dessas propostas extensionistas, não podemos deixar de mencionar o PARU da UFPA que, como programa de ensino, pesquisa e extensão, data de 1992, porém com antecedentes de articulação entre os professores do curso de Serviço Social e os movimentos sociais urbanos de Belém que vêm de 1981, quando um 
grupo de docentes dessa unidade passou a acompanhar e assessorar a luta dos moradores de bairros periféricos da cidade. A partir de então e na década posterior, foram criados campos de estágio supervisionado, assim como o programa em questão, os quais tiveram como objetivo o acompanhamento das reivindicações dos moradores, relacionadas com a luta por habitação, projetos de infraestrutura pública e elaboração de planos locais de habitação, elaboração do Plano Diretor, dentre outros?.

Por sua vez, do ponto de vista dos procedimentos previstos para o planejamento e implementação dos projetos, a maioria manifesta a existência de momentos de trabalho conjunto quando se reúnem docentes (de diversas universidades), alunos (de graduação e pós-graduação, inclusive de diversas instituições de ensino) e lideranças de movimentos sociais e populares, refletindo a existência de práticas de democratização do acesso e de socialização do espaço universitário, na contramão de tendências restritivas que se reproduzem nessas instituições.

Se nos referirmos aos motivos que motorizam a existência dos projetos, em todos eles se manifestam: a) interesses teórico-acadêmicos e profissionais relacionados à área de movimentos sociais; b) motivações ético-políticas e ideológicas vinculadas com a função social da universidade - sendo que, em alguns deles, explicita-se também; c) experiência de trabalho na área ${ }^{8}$. Como viemos afirmando, essas repostas demonstram a preocupação ético-política de segmentos do Serviço Social com a materialização da função social da Universidade, especificamente junto a grupos organizados das classes subalternas, assim como interesses que poderiam estar demonstrando uma retomada da profissão de uma temática que sofreu um paulatino decréscimo nas produções e debates, a partir da década de 1990, ao calor do próprio refluxo da presença política desses sujeitos na cena nacional.

\footnotetext{
${ }^{7}$ Material extraído do questionário preenchido pela coordenação do Programa de Apoio à Reforma Urbana, da UFPA, 2010.

${ }^{8}$ No questionário elaborado corresponde à questão: Motivos que sustentam essa experiência de trabalho com movimentos sociais.
} 
d) Atividades desenvolvidas e o seu significado do ponto de vista do perfil profissional no âmbito do Serviço Social

Cabe agora nos concentrarmos nas atividades desenvolvidas pelos docentes e discentes de Serviço Social que coordenam ou participam dessas experiências, assim como resgatar o seu significado, sua relação com o perfil profissional e a formação universitária. A análise nos permite afirmar que as principais competências nas quais se envolve a profissão de Serviço Social se relacionam e se desdobram num conjunto de atividades que vêm sendo desenvolvidas nas últimas décadas. São elas:

1. apoio à mobilização popular e articulação de diversos sujeitos em luta;

2. qualificação da participação política na elaboração, implementação e controle da política pública;

3. assessoria política e técnica a movimentos sociais;

4. formação teórico-política e cidadã para o fortalecimento da organização popular e constituição de sujeitos coletivos;

5. desenvolvimento de estudos sócio-econômicos (inclusive em articulação interdisciplinar com outras profissões) com o objetivo de potenciar os processos de auto-organização dos grupos subalternos em torno das suas condições de vida e de trabalho, assim como nutrir suas reivindicações para a implementação de possíveis intervenções do poder público;

6. qualificação e politização dos debates (através de palestras, oficinas, dinâmicas de educação popular, assembleias comunitárias, fóruns) acerca dos modos privilegiados de enfrentamento das manifestações ligadas à "questão social", envolvendo técnicos, profissionais, gestores e ainda dando visibilidade aos sujeitos subalternos para que no seu enfrentamento acionem traços de luta e resistência;

7. orientações, encaminhamentos e atendimentos que busquem potencializar a apropriação por parte desses grupos dos procedimentos institucionais e dos serviços que constituem direitos sociais de cidadania. 
Se por outro lado nos referirmos especificamente àqueles projetos que contemplam estágio - ainda que não tenhamos uma vasta amostra sobre os mesmos -, vale a pena trazer alguns objetivos que motivaram sua criação, pois a partir desses casos particulares também poderemos observar elementos do significado dessas experiências.

No exemplo do que posteriormente se consolidaria como PARU (UFPA), a criação de campos de estágio supervisionado junto aos movimentos sociais urbanos de Belém, na década de 1980, esteve relacionada ao acompanhamento das reivindicações desses sujeitos - fundamentalmente vinculadas à habitação -, sendo que, nesse contexto inicial, o próprio docente construía uma relação estreita no processo de intervenção profissional. Não isenta de tensões, a relação desses segmentos críticos do Serviço Social com os movimentos populares teve que contornar conflitos, assumindo o desafio de apostar em outro perfil profissional:

\begin{abstract}
Essa construção de confiança dos movimentos em relação ao nosso papel, à nossa postura, isso foi muito demorado. [...] E nós tivemos depoimentos, [...] para mim trágicos, tipo: 'professora, eu quero saber se essa sua aluna, quando ela estiver do outro lado de uma mesa numa triagem de uma instituição, se ela vai me reconhecer?'. Porque eles já tinham tido experiências nesse sentido?.
\end{abstract}

Marcando um outro momento histórico - caracterizado pela preocupação de retomar a vinculação com os movimentos sociais na contramão do refluxo desse tipo de trabalho -, os motivos de criação da experiência de estágio do Curso de Serviço Social da UFRJ estabelecem ligação com o interesse de alunos e professores de estreitar a relação da profissão com os movimentos sociais. Assim, articulam-se

[...] as necessidades do próprio Serviço Social, como disciplina profissional inserida no âmbito universitário, interessada em promover o desenvolvimento profissional com uma perspectiva emancipatória;

9 Entrevista coletiva realizada a integrantes do PARU, da UFPA, Brasília, agosto de 2010. 
junto com os interesses dos próprios trabalhadores organizados no MST, visando tanto aprimorar a formação dos alunos da Escola de Serviço Social como à ampliação do campo de intervenção profissional junto a sujeitos que atuam na esfera da produção (ACOSTA; DAL MORO, 2008).

Segundo a coordenação do projeto, esse objetivo se materializaria na elaboração de uma proposta de estágio inovadora, em consonância com os princípios que fundamentam o Projeto ético-político do Serviço Social.

Pode-se afirmar que o que motivou essa parceria da Universidade com o MST, foi, em primeiro lugar, a possibilidade de construção de conhecimentos e, em segundo lugar, a efetivação de um campo de estágio para nossos estudantes, tendo um duplo resultado: a elevação da consciência crítica dos estagiários e o crescimento no nível cultural dos acampados e assentados ${ }^{10}$.

Essas observações ganham ainda mais importância quando complementadas com as respostas de nossos entrevistados ao serem indagados sobre o significado do trabalho com movimentos sociais e sua relação com o redimensionamento do perfil profissional - esta última, por sua vez, hipótese central da nossa pesquisa. $\mathrm{Na}$ sua totalidade, afirma-se que a experiência desenvolvida "[...] possibilita a materialização de alguns compromissos assumidos pelo projeto ético-político do Serviço Social com as lutas da classe trabaIhadora [...]", destacando-se a oportunidade de "[...] um redimensionamento teórico, ético e político do perfil profissional à luz das reivindicações e lutas desses movimentos [...]” ou também "[...] da formação de um profissional atento a novas demandas postas por esses sujeitos num cenário de profundas transformações societárias [...]"'11. Ainda sobre a relação dessas experiências com um

\footnotetext{
${ }^{10}$ Material extraído do questionário preenchido pela coordenação do Projeto integrado de parceria em atividades de ensino, pesquisa e extensão com o Movimento dos Trabalhadores Sem Terra (MST), da ESS/UFRJ, 2010.

"As respostas escolhidas correspondem às perguntas do questionário: Significado do trabalho com movimentos sociais: o significado da experiência desenvolvida adquire importância por quê? e Relação com o redimensionamento do perfil profissional: considera que a proposta em questão pode contribuir com o redimensionamento do perfil profissional do Serviço Social?.
} 
potencial redimensionamento do perfil profissional, um dos entrevistados agrega:

A direção dada pela tradição marxista não deverá ser mudada com a influência dos movimentos sociais, mas aprofundada. A realização desta possibilidade será mais visível e impactante se forem massificados cursos de graduação e estágios, mais do que os de extensão ${ }^{12}$.

Ao relatar as estratégias através das quais a experiência de trabalho em questão viabilizaria esse redimensionamento crítico do perfil profissional de alunos e professores envolvidos, os entrevistados destacam: a articulação política com os movimentos sociais; a inclusão das suas demandas no âmbito da universidade pública; o enriquecimento da formação profissional pela incorporação de novas temáticas pouco abordadas pelo Serviço Social'3; a abertura de novos espaços de trabalho profissional junto a movimentos sociais ${ }^{14}$.

Nessa direção, vale a pena trazer mais uma vez, o exemplo do PARU, da UFPA. As integrantes entrevistadas destacam a importância da experiência de estágio e extensão na área de movimentos sociais urbanos não apenas do ponto de vista da formação profissional: politização; amplitude para enfrentar diversas expressões da questão social; sensibilidade para as lutas dos movimentos sociais; maior compreensão das tensões na relação desses sujeitos com as políticas públicas; abertura para o trabalho interdisciplinar (inclusive com áreas distantes, como as ciências exatas). Resgatam, por outro lado, a importância da incorporação de novas temáticas e instrumentos de trabalho pouco familiares para o Serviço Social, como, por exemplo, a cartografia e o geoprocessamento, assinalando o desafio de instrumentalizar também aos movimentos sociais de forma que possam se apropriar dos mesmos para

\footnotetext{
${ }^{12}$ Material extraído do questionário preenchido pela coordenação do Curso Teoria Social e Produção de Conhecimento, da ESS/UFRJ, 2010.

${ }^{13}$ Dentre as novas temáticas especificadas pelos entrevistados, destacam-se: "O trabalho profissional do Assistente Social junto aos movimentos sociais"; "A luta de classes como algo além do discurso acadêmico"; "O debate dos movimentos sociais e da questão agrária". Materiais extraídos dos questionários preenchidos pelos coordenadores dos projetos analisados nesta pesquisa, 2010. ${ }^{14}$ Por exemplo: "Assessoria a movimentos sociais e sindicais". Idem nota anterior.
} 
a potencialização das suas lutas e reivindicações. Nas palavras de uma das entrevistadas:

E uma outra coisa é aquele projeto que eu te falei das novas cartografias, que é uma outra leitura de movimentos, uma metodologia absolutamente criativa, uma coisa muito interessante que é a ideia de cartografar processos. E ao cartografar processos o teu papel como pesquisador é muito mais de uma pesquisa-ação, porque tu tens uma metodologia em que tu queres conhecer como, na cidade de Belém, estão os afrodescendentes, ou os homossexuais, ou os índios, ou os ribeirinhos, enfim, essa cartografia do uso do espaço, de como eles se colocam no espaço; [...] tu tens um fascículo dos afrodescendentes, eles identificaram os lugares sagrados na cidade de Belém, que, para ti, como morador, não têm nenhum valor. [...] Eles levantam os fascículos dizendo que são as armas de luta deles ${ }^{15}$.

Nessa fala, fica claro o enriquecimento que esse tipo de experiências pode possibilitar ao Serviço Social, na perspectiva de afirmação de intervenções profissionais em sintonia com as necessidades e lutas dos movimentos sociais e populares. Esses profissionais entendem que projetos de extensão, experiências de estágio curricular e cursos de Serviço Social criados a partir de parcerias com movimentos sociais e instituições públicas ${ }^{16}$ - em muito casos, aliando a pesquisa acadêmica a esses projetos - podem ser centrais não apenas para a realização da função social da universidade pública brasileira com a classe trabalhadora, mas também para a formação universitária de futuros profissionais e docentes de Serviço Social (e de outras profissões afins envolvidas) que se comprometam com a defesa e ampliação das lutas, reivindicações e direitos sociais dessas maiorias sociais na contramão das tendências de exploração da sociedade capitalista atual.

\footnotetext{
15 Entrevista coletiva realizada a integrantes do PARU, da UFPA, Brasília, agosto de 2010.

${ }^{16}$ Pelo menos três Cursos de Serviço Social vinculados a Universidades Públicas do país discutiram, em 2010, junto a movimentos como o MST, projetos de abertura de Cursos de Serviço Social orientados para movimentos sociais, em especial, do campo. A partir de uma parceria entre o Incra, o MST e a UFRJ, neste ano (2011) se inaugura o primeiro curso de Serviço Social em uma universidade pública, especificamente orientado para movimentos sociais a partir dos esforços coletivos de um grupo de docentes da ESS, da UFRJ.
} 


\section{À GUISA DE CONCLUSÃO}

Quais são os desafios e dificuldades que essas experiências enfrentam na atualidade? A fim de alcançar conclusões que possam orientar futuros desdobramentos de pesquisa, destacamos elementos que não completam nem esgotam a enorme complexidade do tema em questão.

a) Algumas dificuldades se relacionam com a escassez de produção e a pouca representatividade numérica de experiências de trabalho do Serviço Social junto aos movimentos sociais; dificuldades que se acrescentam pela tensão do caráter que ganha essa relação profissão/movimento social nos casos específicos em que não existe um vínculo formal de assalariamento de um profissional.

Por outro lado, essa realidade identificada também na análise de Cardoso; Lopes (2009) se expressa como um nó na hora de se abrir e multiplicar campos de estágio junto a movimentos sociais, sendo pouco expressivo o leque de cursos de Serviço Social que conseguem oferecer essa experiência para os futuros profissionais. Estamos frente a um tema complexo que deverá ser objeto de debate e reflexão futura dos segmentos da categoria interessados em aprofundar a relação de trabalho e articulação político-profissional com os movimentos sociais.

Nos anos 1980 houve um dinamismo das experiências de extensão articuladas ao estágio nos diversos cursos de Serviço Social que sedimentaram alguns 'campos próprios de estágio' voltados para o fortalecimento dos movimentos sociais. Essas experiências apresentavam um limite na época, que era a idéia da necessidade de construção de campos ideais de atuação profissional, em polarização aos campos tradicionais de atuação profissional, que até hoje são maioria. Entretanto, a revisão desta idéia se deu, na maioria dos cursos de Serviço Social, sem um redirecionamento desta concepção, e sim, com o fechamento destas experiências. Entretanto, é necessária a recuperação deste princípio, da realização do estágio em um contexto articulado com a extensão e a pesquisa, sem, entretanto, idealizá-lo (BRAVO; MATOS, 2010, p. 163). 
Assim, é um desafio retomar a valorização da articulação ensino/ pesquisa/extensão, fortalecendo a função social da universidade pública a partir das reivindicações e lutas dos trabalhadores, que são os verdadeiros produtores da riqueza social e raramente têm acesso ao conhecimento socialmente produzido. Na mesma direção, nossas entrevistadas afirmaram, ao fazer um balanço da atualidade à luz do contexto da década de 1980:

Nós sempre tivemos essa tradição de ter uma vinculação entre o ensino e a extensão [... ]. Com esse processo todo de precarização e de controle de um TCU [...] como servidores públicos federais que somos, está acontecendo uma perda, para mim, substancial. [...] O que está acontecendo hoje: quando tu tens uma sobrecarga, um sobretrabalho, nós não damos conta mais de fazer essa dupla condição de ser o professor e ser o técnico que executa. [...] E subverte a relação de ensino-aprendizagem. [...] Para mim isso é uma perda de qualidade fundamental.

E por isso nos cobra a assessoria [se referindo aos movimentos sociais] que nós não podemos dar mais [...]. Aí nós temos esse dilema atual, nós temos que dar conta da pós-graduação, de publicar e escrever, ou seja, então esvazia esse tema do nosso tempo para assessoria [...]. Inclusive, acaba que vai indo para uma pesquisa de certo modo, esvaziada. Eu sempre pergunto: 'você escreve, escreve, escreve, mas isso vai para onde?'. Porque tu tens que escrever e não tem mais o tempo de maturar ${ }^{17}$.

Isso nos conduz a uma outra questão relacionada ao perigo do esvaziamento da relação ensino/pesquisa/extensão a partir das exigências produtivistas e à intensificação do trabalho docente, que caracterizam às instituições de ensino superior na atualidade.

b) Da mesma forma que nas experiências piloto das décadas de 1970-1980, a maioria dos trabalhos com movimentos sociais que são divulgados nos principais eventos da categoria profissional se aloca nas Universidades Públicas (de fato, foi esse o escopo privi-

${ }^{17}$ Falas de integrantes do PARU, da UFPA, em entrevista realizada em Brasília, em agosto de 2010. 
legiado desta pesquisa), provavelmente porque este âmbito possibilite uma maior autonomia técnica e política para a definição de estratégias e prioridades de atuação intelectual e profissional.

Nesse sentido, dois apontamentos são importantes: ao ser a Universidade Pública seu lócus privilegiado, essas experiências devem sortear o conjunto de dilemas que assolam as instituiçõos de ensino (mercantilização acelerada do conhecimento; precarização; produtivismo; elitismo e distanciamento da função social da universidade; sobrecarga de trabalho docente), observando-se, particularmente no caso dos projetos de extensão, recursos que se reduzem à concessão de bolsas acadêmicas para alunos ou rotinas extenuantes de trabalho que deixam pouco tempo disponível para a realização dos mesmos.

De outra parte, mecanismos que vão de encontro ao elitismo da universidade pública devem ser criados para evitar o perigo de que tais experiências se construam de forma desarticulada ou distante do conjunto de instituições de política social que têm a responsabilidade de assegurar direitos sociais - âmbitos privilegiados de atuação profissional, sendo centrais para a disputa da direção social da utilização do fundo público.

c) Outra questão a ser ressaltada se relaciona com o fato de que a totalidade das experiências aqui estudadas prevê mecanismos de socialização dos seus resultados e, em alguns casos, a própria elaboração de produtos - desde cartilhas, material didático, registros gráficos e visuais, elaboração de trabalhos de conclusão de curso a publicações de diversa natureza.

Dentre os espaços políticos e acadêmicos onde tais experiências são socializadas, os entrevistados destacam os eventos da categoria (em especial, CBAS e Enpess) e os fóruns de debate e articulação entre a universidade e os movimentos sociais, e, em menor medida, referenciam a divulgação através de revistas e periódicos científicos de Serviço Social, jornadas de iniciação científica e congressos de extensão, além de órgãos de publicação e comunicação de movimentos sociais. 
Assim, os eventos da categoria são um âmbito destacado de socialização das experiências e suas produções, expressando, de um lado, a necessidade de multiplicar os momentos e recursos de divulgação em revistas e periódicos, seminários internos à universidade, eventos acadêmicos interdisciplinares e nos próprios instrumentos de comunicação popular dos grupos subalternos; de outro, considerando que a relação do Serviço Social com os movimentos e lutas sociais é um desafio que vem sendo retomado pela profissão na busca pelo seu amadurecimento ético, teórico e político, esses dados assinalam a importância de iniciativas como a recente criação dos Grupos Temáticos de Pesquisa (GTPs), no âmbito da Associação Brasileira de Ensino e Pesquisa em Serviço Social (Abepss) - aqui, referimo-nos em especial ao GTP Movimentos Sociais e Serviço Social -, que terão a tarefa de mapear, sistematizar e reunir num acervo comum as diversas produções de tais experiências (ABEPSS, 2009) $)^{18}$.

Entendemos que essas iniciativas serão de grande utilidade para o avanço e o fortalecimento da relação do Serviço Social com os movimentos sociais, do ponto de vista do seu redimensionamento crítico: na recriação de novas funções, atribuições e âmbitos de atuação ancorados nas reivindicações legítimas das maiorias sociais; na incorporação de novas temáticas que enriqueçam o perfil profissional; na formação de futuros profissionais atentos e comprometidos com as demandas emancipatórias das lutas dos grupos subalternos; na produção de pesquisas e experiências de trabalho capazes de desnudar os traços de resistência que esses sujeitos acionam no enfrentamento da questão social; na politização e qualificação dos debates acerca dos modos privilegiados de abordagem das suas manifestações por parte do poder público e do empresariado - na maioria dos casos, na contramão dos processos de auto-organização dos subalternos.

\footnotetext{
${ }^{18}$ Qual é o mapa de cursos de Serviço Social de Universidades Públicas que trabalham com movimentos sociais? E quais são as experiências de trabalho junto a movimentos sociais em instituições de outra natureza (públicas, assistenciais, empresariais, ONGs, sindicatos etc.)? Em que consistem essas experiências? Quais são as atividades desenvolvidas? Qual a relação com a formação e o perfil profissional do Assistente Social? Dentre as experiências universitárias, quantas possuem estágio curricular em movimentos sociais? Quais são e como se divulgam seus principais produtos? Essas são algumas das perguntas que podem nortear a indagação.
} 


\section{REFERÊNCIAS}

ABEPSS. A ABEPSS e o fortalecimento da pesquisa na Área de Serviço Social: a estratégia dos Grupos Temáticos de pesquisa (GTPs). 2009. Disponível em: <http://www.abepss.org.br/briefing/documentos/GTPs_Novembro_de_2009_Final.pdf>. Acesso em: 8 abr. 2010.

ABREU, Marina Maciel. Serviço Social e a organização da cultura: perfis pedagógicos da prática profissional. São Paulo: Cortez, 2002.

ACOSTA, Luis; DAL MORO, Maristela. Serviço Social e Movimento dos Trabalhadores Rurais Sem Terra (MST): uma experiência de estágio. ENCONTRO NACIONAL DE PESQUISADORES EM SERVIÇO SOCIAL, 11., 2008, São Luiz. Anais... São Luiz: ABEPSS, 2008.

BICUDO, Valeria Rosa. Projeto de Extensão Observatório de Lutas Sociais: constituição de sujeitos coletivos e políticas públicas. Rio das Ostras: Puro-UFF, 2008.

- Relatório das ações de extensão do Projeto Observatório de Lutas Sociais: constituição de sujeitos coletivos e políticas públicas. Rio das Ostras: Puro-UFF, 2008.

BRAVO, Maria Inês Souza; MATOS, Maurílio Castro de. O potencial de contribuição do Serviço Social na assessoria aos movimentos sociais pelo direito à saúde. In BRAVO, Maria Inês Souza; MATOS, Maurílio Castro de (Org.). Assessoria, Consultoria e Serviço Social. 2. ed. São Paulo: Cortes, 2010. p. 141-169.

CARDOSO, Franci Gomes; LOPES, Josefa Batista. O trabalho do assistente social nas organizações da classe trabalhadora. In: CFESS; ABEPSS. Serviço Social: direitos e competências profissionais. Brasília: CFESS-Abepss, 2009.

CARDOSO, Franci Gomes; MACIEL, Marina. Mobilização social e práticas educativas. In: SERVIÇO Social: direitos sociais e competências profissionais. Brasília: CFESS-Abepss, 2009. 
CRUZ, Suenya Santos da. Relatório final do projeto de extensão Curso de formação política para militantes da saúde pública. Rio das Ostras: Puro-UFF, 2008.

DAL MORO, Maristela; ACOSTA, Luis Eduardo. Projeto integrado de parceria em atividades de ensino, pesquisa e extensão com o Movimento dos Trabalhadores Sem Terra (MST), Locuss-UFRJ. Rio de Janeiro, jun. 2005.

DURIGUETTO, Maria Lúcia. A temática dos movimentos sociais e sua incorporação no Serviço Social. 1996. Dissertação (Mestrado em Serviço Social) - Programa de Pós-Graduação em Serviço Social, Universidade Federal do Rio de Janeiro, 1996.

FALEIROS, Vicente de Paula. Serviço Social nas instituições: hegemonia e prática. Serviço Social \& Sociedade, São Paulo, n. 17, p. 3040, abr. 1985.

. Trabajo Social e Instituciones. Buenos Aires: Humanitas, 1992.

FARAGE, Eblin et al. Assessoria em questões de cidadania a movimentos sociais e populares: parcerias inter-universidades para a gestação de processos de formação política e humana para militantes sociais. Rio das Ostras: Puro-UFF, 2010. Projeto de Extensão.

GRAMSCI, Antonio. Cadernos do cárcere. Rio de Janeiro: Civilização Brasileira, 2000a. v. 3: Notas sobre o Estado e a Política.

- Cadernos do cárcere. Rio de Janeiro: Civilização Brasileira, 2000b. v. 5: Notas sobre a história da Itália.

LIMA, Sandra Amêndola Barbosa et al. Movimentos Sociais Urbanos e Serviço Social. Serviço Social \& Sociedade, São Paulo, ano 3, n. 8, p. 117-135, mar. 1982.

MARRO, Katia. A rebelião dos que "sobram": reflexões sobre a organização dos trabalhadores desempregados e os mecanismos sócio-assistenciais de contra-insurgência na Argentina contemporânea. 2009. Tese (Doutorado em Serviço Social). Programa de Pós-Graduação em Serviço Social, Universidade Federal do Rio de Janeiro, 2009. 
. Serviço Social em movimento: experiências universitárias de trabalho e articulação com movimentos e organizações das classes subalternas na contemporaneidade: relatório de pesquisa. Rio das Ostras: UFF-Puro, 2011.

MARRO, Katia; DULCICH, Ramiro. Serviço Social em movimento: experiências universitárias de trabalho e articulação com movimentos e organizações das classes subalternas na contemporaneidade: projeto de pesquisa. Rio das Ostras: UFF-Puro, 2009.

MARRO, Katia; PESSOA, Natália da Silva. Uma análise introdutória da relação do Serviço Social com as organizações das classes subalternas. CONGRESSO BRASILEIRO DE ASSISTENTES SOCIAIS, 13., 2010, Brasília. Anais... Brasília: CFESS/ABEPSS/ENESSO, 2010.

MARRO, Katia et al. A participação do Serviço Social em experiências de formação dos movimentos sociais das classes subalternas. ENCONTRO NACIONAL DE PESQUISADORES EM SERVIÇO SOCIAL, 12., 2010, Rio de janeiro. Anais... Rio de Janeiro: ABEPSS, 2010.

MATOS, Maurílio Castro de. Assessoria e Consultoria: reflexões para o Serviço Social. In: BRAVO, Maria Inês Souza; MATOS, Maurílio Castro de (Org.). Assessoria, Consultoria e Serviço Social. 2. ed. São Paulo: Cortes, 2010. p. 29-57.

MOISES, José Álvaro; SERRA, Rose Mary Sousa. Movimentos populares, alternativas de políticas sociais e a organização da categoria. In: ABRAMIDES, M. Beatriz C.; CABRAL, M. do Socorro Reis. (Org.). O Serviço social nas relações sociais: movimentos populares e alternativas de políticas sociais. São Paulo: Cortez: ANAS, 1987.

PIZETTA, Adelar. A formação política no MST: um processo em construção. Revista OSAL, Buenos Aires, ano 8, n. 22, p. 241-250, set. 2007.

RAICHELIS, Raquel; ROSA, Cleisa. Considerações a respeito da prática do Serviço Social em movimentos sociais: fragmentos de uma experiência. Serviço Social \& Sociedade, São Paulo, ano 3, n. 8, p. 69-83, mar. 1982. 
- O Serviço Social e os movimentos sociais: análise de uma prática. Serviço Social \& Sociedade, São Paulo, ano 6, n. 19, p. 74-97, dez. 1985 .

SILVA e SILVA, Maria Ozanira da (Coord.). O Serviço Social e o Popular: resgate teórico-metodológico do projeto profissional de ruptura. São Paulo: Cortez, 1995.

SILVA, Olinda Rodriguez da. Programa Universidade Popular em Direitos Humanos (PUPDH). Belém: UFPA, 2009.

SILVEIRA, Maria Lidia Souza da et al. Teorias Sociais e Produção de Conhecimento, CFCH/NEPP-DH/UFRJ. Rio de Janeiro, 2008. Projeto Curso de Extensão.

TOFIK, D. S. et al. O Serviço Social e os movimentos sociais: uma experiência de trabalho em loteamentos clandestinos. Serviço Social \& Sociedade, São Paulo, n. 5, p. 131-145, 1981.

V CONGRESSO Brasileiro de Assistentes Sociais. In: O SERVIÇO Social nas relações sociais: movimentos populares e alternativas de políticas sociais. 2. ed. São Paulo: Cortez: Anas, 1989.

VI CONGRESSO Brasileiro de Assistentes Sociais - Congresso Chico Mendes. In: SERVIÇO Social: as respostas da categoria aos desafios conjunturais. São Paulo: Cortez: Anas, 1991. 